\title{
Tratamento descentralizado de esgotos de empreendimentos comercial e residencial empregando a ecotecnologia dos wetlands construídos
}

\author{
Decentralized wastewater treatment of commercial and \\ residential buildings using the ecotechnology of \\ constructed wetlands
}

\begin{tabular}{|c|c|}
\hline & $\begin{array}{l}\text { Camila Maria Trein } \\
\text { Catiane Pelissari } \\
\text { Heike Hoffmann } \\
\text { Christoph Julius Platzer } \\
\text { Pablo Heleno Sezerino }\end{array}$ \\
\hline $\begin{array}{l}\text { Camila Maria Trein } \\
\text { Universidade de Rio Verde } \\
\text { Nova Caiapônia - GO - Brasil }\end{array}$ & 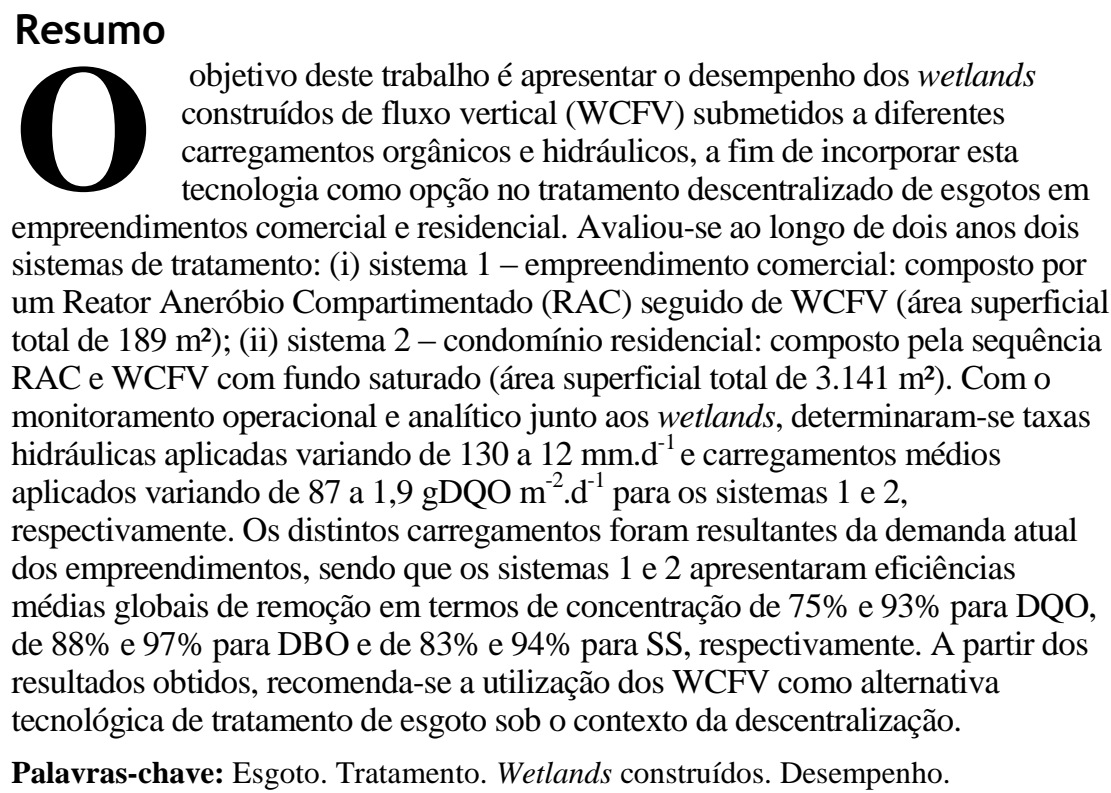 \\
\hline $\begin{array}{l}\text { Catiane Pelissari } \\
\text { Universidade Federal de Santa }\end{array}$ & Abstract \\
\hline Florianópolis - SC - Brasil & $\begin{array}{l}\text { The aim of this study is to show the performance of vertical flow constructed } \\
\text { wetlands (VFCW) applied to wastewater treatment from commercial and } \\
\text { residential buildings under different organic and hydraulic loading rates. }\end{array}$ \\
\hline $\begin{array}{r}\text { Heike Hoffmann } \\
\text { Rotária do Brasil Ltda. } \\
\text { Florianópolis - SC - Brasil }\end{array}$ & $\begin{array}{l}\text { During two years two systems were evaluated: }(i) \text { system } 1 \text {-commercial } \\
\text { building: compound by one Baffle Anaerobic Reactor }(B A C) \text { followed by } \\
\text { VFCW (superficial area } 189 \mathrm{~m}^{2} \text { ); (ii) system } 2 \text { - residential building: }\end{array}$ \\
\hline $\begin{array}{l}\text { Christoph Julius Platzer } \\
\text { Rotária do Brasil Ltda. } \\
\text { Florianópolis - SC - Brasil }\end{array}$ & $\begin{array}{l}\text { compound by one BAC followed by VFCW (superficial area } 3,141 \mathrm{~m}^{2} \text { ). The } \\
\text { operational and analytic monitoring of the wetlands systems determined } \\
\text { hydraulic loading rate applied from } 130 \text { to } 12 \mathrm{~mm} . \mathrm{d}^{-1} \text { and organic loading } \\
\text { rate applied from } 87 \text { to } 1.9 \mathrm{gCOD} \text {, for systems } 1 \text { and } 2 \text { respectively. The }\end{array}$ \\
\hline $\begin{array}{r}\text { Pablo Heleno Sezerino } \\
\text { Universidade Federal de Santa } \\
\text { Catarina } \\
\text { Florianópolis - SC - Brasil }\end{array}$ & $\begin{array}{l}\text { different loadings applied were due to actual demand and the systems } 1 \text { and } 2 \\
\text { showed average concentration removals efficiencies of } 75 \% \text { and } 93 \% \text { to COD, } \\
\text { of } 88 \% \text { and } 97 \% \text { to BOD and of } 83 \% \text { and } 94 \% \text { to SS, respectively. These } \\
\text { results lead us to recommend the use of VFCW as a decentralized wastewater }\end{array}$ \\
\hline $03 / 02 / 15$ & \\
\hline 28/07/15 & Keywords: Wastewater. Treatment. Constructed wetlands. Performance. \\
\hline
\end{tabular}

TREIN, C. N.; PELISSARI, C.; HOFFMANN, H.; PLATZER, C. J.; SEZERINO, P. H. Tratamento descentralizado de esgotos de empreendimentos comercial e residencial empregando a ecotecnologia dos wetlands construídos. Ambiente Construído, Porto Alegre,v. 15, n. 4, p. 351-367, out./dez. 2015. ISSN 1678-8621 Associação Nacional de Tecnologia do Ambiente Construído. http://dx.doi.org/10.1590/s1678-86212015000400055 


\section{Introdução}

Diversas tecnologias podem ser aplicadas sob o contexto do tratamento descentralizado de esgotos, estando sua escolha relacionada com as condições específicas do local, dos recursos financeiros disponíveis e do requerimento legal de lançamento do efluente tratado. Essas tecnologias combinadas com um sistema clássico de esgotamento sanitário centralizado, compreendendo a coleta, o transporte, o tratamento e a disposição final, auxiliarão na universalização dos serviços de saneamento.

O processo de tratamento descentralizado de esgoto passa pelo nível coletivo (pequenas comunidades e/ou conjunto de edificações), até o individual, conhecido na literatura internacional como sistema on site. Inúmeras são as tecnologias aplicáveis, sendo algumas delas apresentadas nas normas brasileiras NBR 7229 (ABNT, 1993) e NBR 13969 (ABNT, 1997), as quais destacam a necessidade da promoção, minimamente, dos níveis de tratamento primário e secundário.

Como os sistemas descentralizados têm grande flexibilidade de construção, a definição do arranjo tecnológico deve assegurar proteção da qualidade do meio ambiente, a conservação de recursos, a reutilização de água e a reciclagem de nutrientes, necessitando em muitos casos promover o tratamento em nível avançado (HO, 2005).

Diferentes modalidades de decantodigestores, tais como o tanque séptico (TS) com câmara simples ou câmaras duplas, além dos reatores anaeróbios compartimentados com subdivisões longitudinais de câmaras (RAC, traduzido do inglês Anaerobic Baffled Reactor), são as alternativas usualmente mais empregadas para a promoção do tratamento primário de esgoto.

Para o tratamento secundário, as tecnologias mais indicadas para a abordagem descentralizada são os reatores que se baseiam no processo depurativo de biomassa aderida em material suporte, tais como os filtros anaeróbios, biofiltros aerados submersos, filtros de areia, valas de filtração e a ecotecnologia conhecida como wetlands construídos (MASSOUD; TARHINI; NASR, 2009; SEZERINO et al., 2012).

Já para a promoção do tratamento avançado, enfatizando a remoção de sólidos suspensos remanescentes e a transformação do nitrogênio, Metcalf e Eddy (1991) destacam, entre outras tecnologias, unidades de filtração, tais como filtros de areia, filtros biológicos percoladores (trickling filters) e os wetlands construídos de escoamento vertical.

O objetivo deste trabalho é apresentar a eficiência de wetlands construídos de escoamento vertical submetidos a diferentes carregamentos orgânicos e hidráulicos, aplicados ao tratamento de esgotos de empreendimentos comercial e residencial.

\section{Conceitos e critérios relacionados aos wetlands construídos}

Os wetlands construídos são capazes de promover a depuração de águas residuárias através de uma combinação de processos físicos, químicos e biológicos, que incluem sedimentação, precipitação, adsorção às partículas do material filtrante, assimilação pelos tecidos das plantas e transformações microbiológicas (VYMAZAL; KROPFELOVÁ, 2008).

Wetlands construídos são sistemas concebidos e construídos para utilizar os processos naturais, que envolvem a vegetação, material filtrante e microorganismos, para auxiliar no tratamento de águas residuárias. Podem ser classificados em dois grupos, superficial e subsuperficial, sendo este último subdividido em função do fluxo hidráulico como horizontal e vertical (Figura 1).

Os wetlands construídos de escoamento subsuperficial de fluxo vertical (WCFV) são módulos implantados no terreno, com o fundo e as laterais impermeabilizados, preenchido com material de recheio (usualmente areia e brita), onde as macrófitas do tipo emergentes são plantadas diretamente (PHILLIPI; SEZERINO, 2004). Nessa concepção o afluente é bombeado intermitentemente, em pulsos, sobre a superfície do filtro, inundando-o e percolando gradativamente na seção vertical, sendo o efluente tratado coletado no fundo por meio de tubulações de drenagem (Figura 2).

Nos WCFV os princípios básicos de tratamento englobam a filtração e a formação de biofilme aderido ao meio suporte. Esses sistemas operam com a alimentação intermitente do afluente em períodos curtos, seguido de intervalos longos de descanso, procedimento que ajuda a evitar a obstrução do filtro, além de aumentar a transferência de oxigênio para o interior do meio filtrante, contribuindo para a alta remoção dos poluentes (HOFFMANN et al., 2011). 
Figura 1 - Classificação dos wetlands construídos - em destaque o tipo de wetland utilizado neste estudo

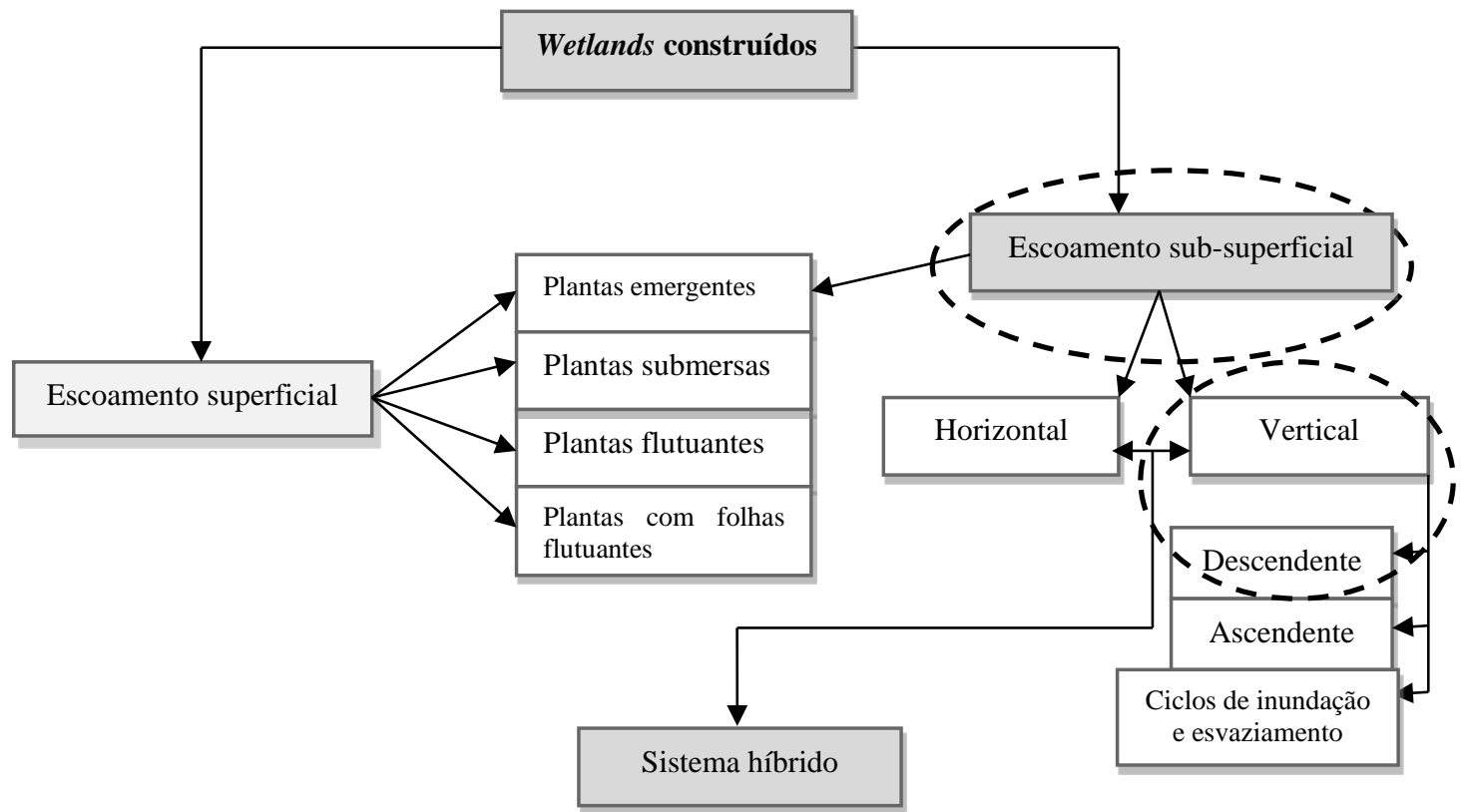

Fonte: adaptado de Vymazal e Kroepfelová (2008).

Figura 2 - Corte longitudinal esquemático da sequência decantador-digestor seguido de WCFV

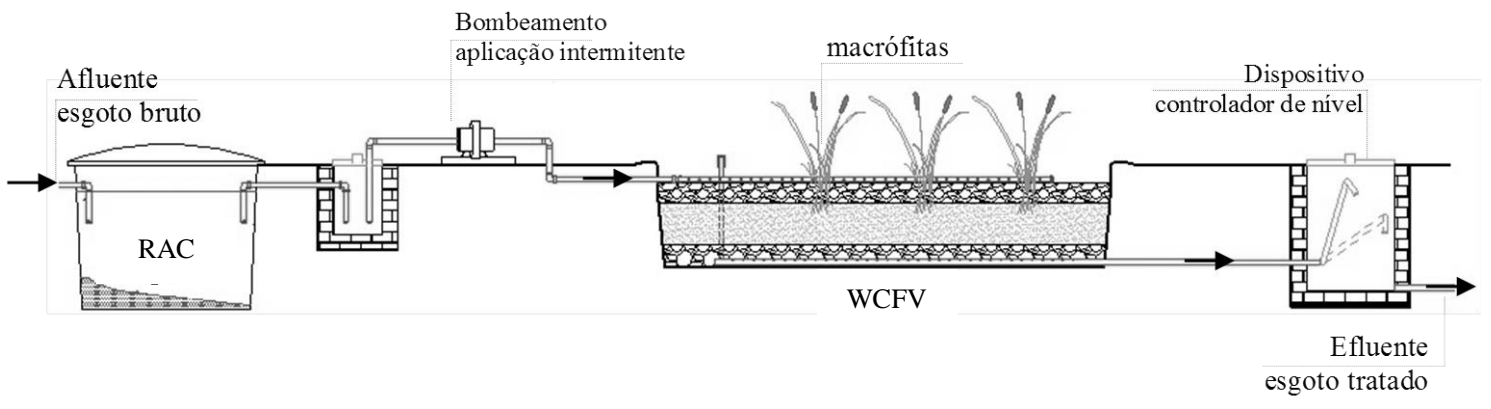

O dimensionamento dos WCFV é dependente das taxas hidráulicas e cargas orgânicas aplicadas sobre a área superficial do módulo. Recomendações de literatura apontam para valores de taxa hidráulica variando de 100 a $120 \mathrm{~mm}^{-\mathrm{d}^{-1}}$ em regiões de clima frio, e para regiões de clima quente até um limite de $250 \mathrm{~mm} \cdot \mathrm{d}^{-1}$ (PLATZER, 1999). Em relação ao carregamento orgânico limitam-se valores máximos de $30 \mathrm{~g}$ DQO $\mathrm{m}^{-2} \cdot \mathrm{d}^{-1}$ para climas frios e cerca de 40 a $70 \mathrm{~g}$ DQO $\mathrm{m}^{-2} \cdot \mathrm{d}^{-1}$ em climas quentes, o que, para efluentes domésticos, corresponde a aproximadamente 20 a $35 \mathrm{~g}$ DBO $\mathrm{m}^{-2} \cdot \mathrm{d}^{-1}$ (PLATZER et al., 2007; HOFFMAN et al., 2011). Para as condições de clima subtropical, encontradas no sul do Brasil, Sezerino (2006) destaca valores de $230 \mathrm{~mm} . \mathrm{d}^{-1}, 41$ g DQO m $\mathrm{m}^{-2} \cdot \mathrm{d}^{-1}$ e $15 \mathrm{~g} \mathrm{SS} \mathrm{m} \mathrm{m}^{-2} \cdot \mathrm{d}^{-1}$, para que ocorra remoção de matéria orgânica superior a $80 \%$ e uma efetiva nitrificação do nitrogênio amoniacal afluente.

Tem-se ainda como critério de dimensionamento de WCFV a verificação do balanço de oxigênio, de onde se espera que a demanda de oxigênio para a oxidação da matéria orgânica carbonácea e para a nitrificação seja menor que os valores de oxigênio que adentram o módulo de wetland por meio da convecção e difusão do ar atmosférico para o meio filtrante, além da transferência de oxigênio realizada pelas macrófitas. Vários modelos de balanço de oxigênio são propostos, destacando-se o modelo apresentado por Platzer (1999).

\section{Metodologia}

Dois diferentes sistemas de tratamento descentralizados de esgoto (Figura 3), localizados na região de Florianópolis, SC, foram monitorados 
ao longo de 2 anos por meio de aferições de vazões e coletas de amostras para análises físico-químicas do afluente e efluente.

Em ambos os sistemas a alimentação do esgoto pós-decantodigestor sobre a superfície do wetland foi realizada por bombeamento acoplada ao último compartimento do RAC, acionados alternadamente por um mecanismo automatizado utilizando boia de nível. Todo o sistema de recalque foi automatizado e controlado on-line com o programa SCADAweb $^{\circledR} \quad$ (Supervisory Control And Data Acquisition) (Figura 4).

Com acesso a esse banco de dados de acionamento das bombas, foi possível trabalhar com as informações armazenadas utilizando uma planilha eletrônica para transformar os dados de lógica (ligado/desligado) e horários de mudança de situação das bombas em tempo de funcionamento por pulso, e assim obter o comportamento de vazão de alimentação dos WCFV em ambos os sistemas.
Além da intermitência do efluente sobre a superfície dos WCFV, estes possuem intermitência no funcionamento dos quadrantes, isto porque cada sistema está dividido em quatro quadrantes e a alimentação ocorre de forma cruzada, sempre alimentando 2 e alternando para os outros 2 quadrantes a cada 30 dias.

O WCFV referente ao sistema 1 trabalha com drenagem livre e atende aproximadamente 250 pessoas, distribuídas em um período de $24 \mathrm{~h}$. O WCFV do sistema 2 trabalha com $20 \mathrm{~cm}$ de fundo saturado e recebe contribuição de 100 moradores, $5 \%$ do previsto para a população final (2.200 pessoas). Neste caso, a saturação é proporcionada pela instalação de um dispositivo controlador de nível na saída da tubulação de fundo, conforme ilustrado na Figura 2.

O monitoramento por meio de análises físicoquímicas foi realizado mensalmente, durante 20 meses entre os anos de 2013 e 2014, ou seja, após 5 e 8 anos de operação dos sistemas 1 e 2 respectivamente. 


\section{Figura 3 - Leiaute e detalhes dos sistemas de tratamento}

Sistema 1 - Biguaçu/SC

(latitude 27³2'10”; longitude $48^{\circ} 38^{\prime} 47^{\prime \prime}$ )

implantado em 2009

- Área superficial total $=189 \mathrm{~m}^{2}$

Composto por 4 quadrantes de $47,25 \mathrm{~m}^{2}$, cada

- Profundidade do leito filtrante $=0,90 \mathrm{~m}$

$(0,10 \mathrm{~m}$ brita na camada superior; $0,60 \mathrm{~m}$ de areia grossa na camada intermediária; $0,20 \mathrm{~m}$ de brita na camada inferior de drenagem de fundo)

- Areia grossa $\left(\mathrm{d}_{10}=0,36 \mathrm{~mm} ; \mathrm{U}=5,3\right)$

- Impermeabilização com manta PEAD

- Macrófita utilizada $=$ Cyperus papiros nano



equivalente populacional 250 pessoas

Sistema 2 - Palhoça/SC

(latitude $27^{\circ} 45^{\prime} 4.82^{\prime \prime}$; longitude 48³7’39.35”)

implantado em 2005

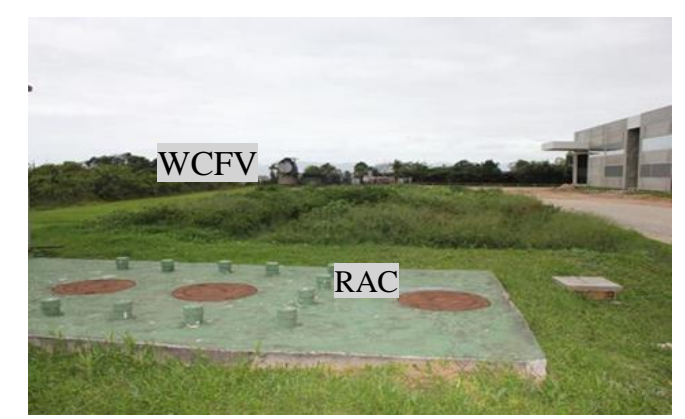

- Área superficial total $=3.141 \mathrm{~m}^{2}$

Composto por 4 quadrantes

- Profundidade do leito filtrante $=0,90 \mathrm{~m}$

$(0,10 \mathrm{~m}$ brita na camada superior; $0,50 \mathrm{~m}$ de areia grossa na camada intermediária; $0,10 \mathrm{~m}$ de brita na camada inferior de drenagem de fundo)

- Areia grossa $\left(\mathrm{d}_{10}=0,30 \mathrm{~mm} ; \mathrm{U}=4,84\right)$

- Impermeabilização com manta PEAD

- Macrófita utilizada = Cyperus papiros

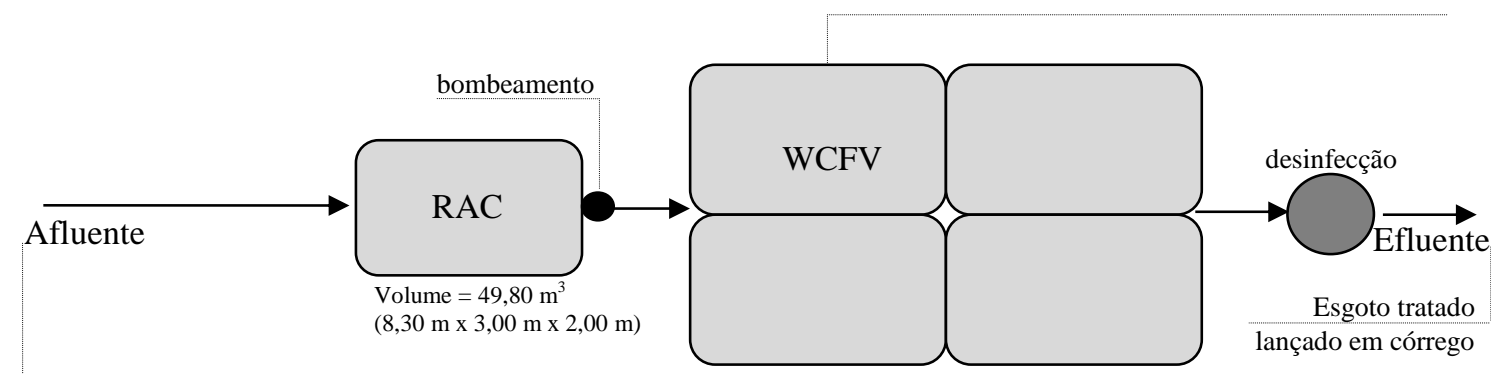

equivalente populacional máximo $=2.200$ pessoas atualmente o sistema recebe contribuição de 100 pessoas (referente a $5 \%$ )

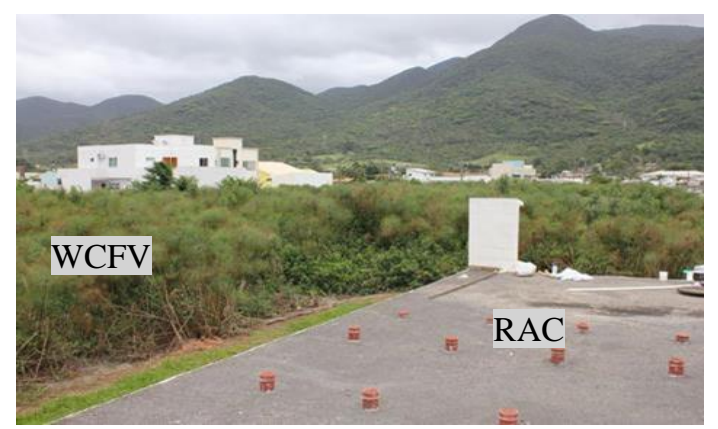


Figura 4 - Exemplo do controle on-line pelo sistema SCADAweb ${ }^{\circledR}$ dos instantes de acionamento das bombas de alimentação do WCFV em ambos os sistemas

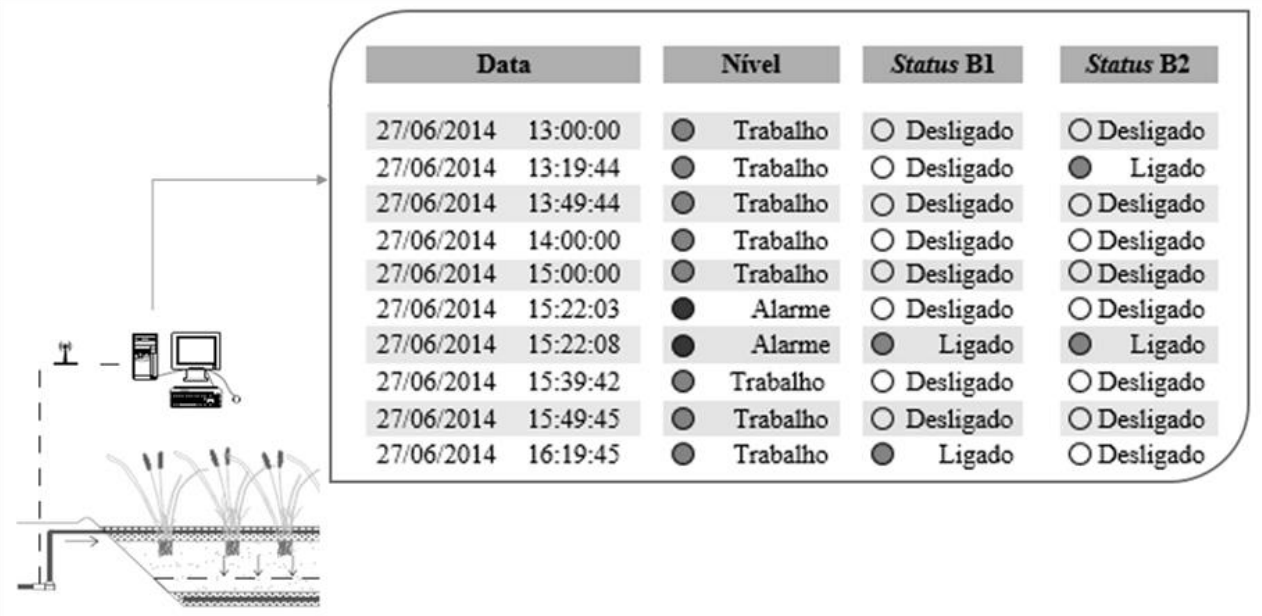

Fonte: extraído de software de sensoriamento remoto disponibilizado pela empresa operadora das estações.

O monitoramento foi dividido em duas etapas:

(a) a primeira etapa, referente aos meses de abril a dezembro de 2013, compreendeu amostragens simples no primeiro compartimento do RAC (esgoto bruto), entrada e saída (esgoto tratado) do WCFV, em ambos os sistemas. Neste período, as coletas foram, em sua maioria, quinzenais e realizadas sempre, em uma única vez, no período da manhã; e

(b) a segunda etapa, referente aos meses de fevereiro a novembro de 2014, prosseguiu-se com as coletas de amostras simples do esgoto bruto e coletas de amostras compostas no afluente e efluente dos WCFV de ambos os sistemas. As coletas foram quinzenais, sendo as coletas compostas realizadas das $8 \mathrm{~h}$ às $17 \mathrm{~h}$ (totalizando 10 h), com coletas de alíquotas de $500 \mathrm{~mL}$ a cada hora, completando $5 \mathrm{~L}$ ao final de cada dia.

Para verificar se houve diferença significativa entre as amostras simples e compostas coletadas nos dois sistemas utilizou-se a análise de variância ANOVA por meio do software Microsoft Excel ${ }^{\circledR}$. Para essa análise consideraram-se duas hipóteses:

$\mathrm{H}_{0}$ : não há diferença entre as amostras; $\mathrm{e}$

$\mathrm{H}_{1}$ : há diferença entre as amostras.

Se $\mathrm{p}>\alpha$, aceita-se $\mathrm{H}_{0}$ e se $\mathrm{p}<\alpha$, rejeita-se $\mathrm{H}_{0}$. No presente estudo, o teste de variância ANOVA foi aplicado com nível de significância de 5\% ( $\alpha=$ $0,05)$.

Os parâmetros físico-químicos avaliados foram potencial hidrogeniônico $(\mathrm{pH})$, alcalinidade, demanda química de oxigênio (DQO), demanda bioquímica de oxigênio (DBO), sólidos em suspensão (SS), nitrogênio amoniacal $\left(\mathrm{N}-\mathrm{NH}_{4}{ }^{+}\right.$), nitrogênio nitrito $\left(\mathrm{N}^{-\mathrm{NO}_{2}}{ }^{-}\right)$, nitrogênio nitrato $(\mathrm{N}-$ $\left.\mathrm{NO}_{3}{ }^{-}\right)$, fósforo ortofosfato $\left(\mathrm{P}_{-} \mathrm{PO}_{4}{ }^{3-}\right)$ e E. coli, seguindo recomendações do Standard Methods (APHA-AWA-WEF, 1998 e 2005), com exceção do nitrogênio amoniacal, cuja metodologia segue recomendações de Vogel (1998).

\section{Resultados}

\section{Caracterização do esgoto bruto e desempenho de tratamento da unidade de tratamento primário}

Ressaltando as particularidades de cada sistema, com o sistema 1 apresentando uma característica de afluente oriundo das instalações sanitárias e do refeitório de uma empresa de embalagens, e o sistema 2 com o afluente oriundo de residências unifamiliares transportadas por uma rede coletora do condomínio residencial, destaca-se na Tabela 1 as características da qualidade físico-química dos respectivos esgotos brutos.

Apesar das diferenças entre as concentrações do material orgânico carbonáceo, expresso em termos de DQO e DBO, entre os sistemas 1 e 2, a relação DQO/DBO dos afluentes foi em média igual a 1,85 e 1,75 nos sistemas 1 e 2 respectivamente. Essas relações indicam esgotos com grande biodegradabilidade, similares às características de esgoto doméstico (VON SPERLING, 1995).

A partir das concentrações médias afluentes e do desempenho de tratamento das unidades de tratamento primário, realizado pelos reatores compartimentados - RAC (Tabela 2), pode-se, em conjunto com a obtenção da vazão e das taxas hidráulicas, determinar os carregamentos 
orgânicos médios de alimentação dos WCFV, parâmetro este considerado de fundamental importância para seu dimensionamento, bem como para identificar o desempenho das unidades primárias e secundárias/avançadas.

\section{Carregamento hidráulico}

A partir das medições de vazão ao longo do ano de 2014 junto ao sistema 1, obteve-se para o WCFV uma vazão média afluente de 12.200 L.d ${ }^{-1}$, alimentado em média 6 vezes por dia. Contudo, verificou-se nesse sistema, através do gerenciamento remoto, que houve registros de acionamento das bombas variando de 1 até 18 bombeamentos por dia.

Como se trata de uma empresa, esses sistemas recebem grandes variações e picos de vazão afluente, justificada pela rotina da produção de esgoto dentro da empresa que tem $24 \mathrm{~h}$ de funcionamento. Considerando essa vazão afluente e a área superficial de dois quadrantes, ou seja, $94,5 \mathrm{~m}^{2}$, a taxa hidráulica média aplicada nesse sistema foi de $130 \mathrm{~mm} \cdot \mathrm{d}^{-1}$.
Para o sistema 2 a vazão média diária afluente do WCFV foi de $18.065{\mathrm{~L} . d^{-1}}^{-}$, distribuídas em média por quatro alimentações diárias. Contudo, também verificaram-se através do acionamento remoto mais registros de acionamento das bombas, neste caso chegando até 14 bombeamentos por dia, com tempo de funcionamento da bomba de apenas alguns minutos.

Neste último caso, a vazão média se manteve próximo do que a NBR 7229 (ABNT, 1993) recomenda, estimada para uma população de 100 habitantes (5\% da população prevista), com contribuição diária de 160 L.hab ${ }^{-1}$. A taxa hidráulica média aplicada nesse sistema foi de 11,6 $\mathrm{mm} \cdot \mathrm{d}^{-1}$ para os dois conjuntos de quadrantes.

Platzer (1999) recomenda como critério de dimensionamento de duas a três alimentações diárias. Já Hoffman et al. (2011) recomendam aplicações de 4 a 12 vezes por dia. Menores números de alimentações correspondem a maior tempo de repouso do filtro, favorecendo a renovação do oxigênio dentro do maciço filtrante. Além disso, a alimentação em menor número diminui a possibilidade de acúmulo de efluente retido na superfície (KAYSER; KUNST, 2005).

Tabela 1 - Características médias de qualidade físico-química e bacteriológica do esgoto bruto nos sistemas 1 e 2

\begin{tabular}{lcc}
\hline \multicolumn{1}{c}{ Parâmetros } & Sistema 1 & Sistema 2 \\
\hline $\mathrm{pH}$ & $7,2 \pm 0,7(\mathrm{n}=27)$ & $7,0 \pm 0,3(\mathrm{n}=28)$ \\
Alcalinidade $\left(\mathrm{mgCaCO}_{3} \cdot \mathrm{L}^{-1}\right)$ & $316 \pm 106(\mathrm{n}=27)$ & $228 \pm 54(\mathrm{n}=28)$ \\
DQO $\left(\mathrm{mg} \cdot \mathrm{L}^{-1}\right)$ & $724 \pm 395(\mathrm{n}=27)$ & $276 \pm 138(\mathrm{n}=28)$ \\
$\mathrm{DBO}\left(\mathrm{mg} \cdot \mathrm{L}^{-1}\right)$ & $390 \pm 190(\mathrm{n}=9)$ & $158 \pm 48(\mathrm{n}=9)$ \\
$\mathrm{SS}\left(\mathrm{mg} \cdot \mathrm{L}^{-1}\right)$ & $134 \pm 126(\mathrm{n}=27)$ & $54 \pm 51(\mathrm{n}=28)$ \\
$\mathrm{N}-\mathrm{NH}_{4}^{+}\left(\mathrm{mg} \cdot \mathrm{L}^{-1}\right)$ & $103 \pm 37(\mathrm{n}=27)$ & $51 \pm 18(\mathrm{n}=28)$ \\
$\mathrm{N}_{-} \mathrm{NO}_{2}^{-}\left(\mathrm{mg} \cdot \mathrm{L}^{-1}\right)$ & $0,2 \pm 0,1(\mathrm{n}=27)$ & $0,1 \pm 0,1(\mathrm{n}=28)$ \\
$\mathrm{N}-\mathrm{NO}_{3}^{-}\left(\mathrm{mg} \cdot \mathrm{L}^{-1}\right)$ & $0,2 \pm 0,3(\mathrm{n}=27)$ & $\mathrm{ND}$ \\
$\mathrm{P}-\mathrm{PO}_{4}{ }^{3-}\left(\mathrm{mg} \cdot \mathrm{L}^{-1}\right)$ & $27 \pm 11(\mathrm{n}=27)$ & $15 \pm 8(\mathrm{n}=28)$ \\
E. coli $\left(\mathrm{NMP} .100 \mathrm{~mL}^{-1}\right)$ & $1,0210^{8}(\mathrm{n}=11)$ & $3,2110^{7}(\mathrm{n}=14)$ \\
\hline
\end{tabular}

Nota: Legenda:

$\mathrm{n}=$ número de amostragens válidas.

$\mathrm{ND}=$ não detectável pelo método analítico.

Tabela 2 - Características médias de qualidade do efluente do tratamento primário dos sistemas 1 e 2

\begin{tabular}{|c|c|c|c|c|}
\hline Parâmetros & Sistema 1 & Remoção* & Sistema 2 & Remoção* \\
\hline $\mathrm{pH}$ & $7,0 \pm 0,6(n=27)$ & & $6,9 \pm 0,4(n=28)$ & \\
\hline Alcalinidade $\left(\mathrm{mgCaCO}_{3} \mathrm{~L}^{-1}\right)$ & $304 \pm 108(n=27)$ & & $213 \pm 63(n=28)$ & \\
\hline $\mathrm{DQO}\left(\mathrm{mg} \cdot \mathrm{L}^{-1}\right)$ & $603 \pm 108(\mathrm{n}=27)$ & $17 \%$ & $157 \pm 60(\mathrm{n}=28)$ & $43 \%$ \\
\hline DBO $\left(\mathrm{mg} \mathrm{L}^{-1}\right)$ & $329 \pm 134(n=9)$ & $16 \%$ & $83 \pm 28(\mathrm{n}=9)$ & $47 \%$ \\
\hline $\mathrm{SS}\left(\mathrm{mg} \cdot \mathrm{L}^{-1}\right)$ & $109 \pm 75(\mathrm{n}=27)$ & $19 \%$ & $27 \pm 18(\mathrm{n}=28)$ & $50 \%$ \\
\hline $\mathrm{N}-\mathrm{NH}_{4}^{+}\left(\mathrm{mg} \cdot \mathrm{L}^{-1}\right)$ & $98 \pm 35(\mathrm{n}=27)$ & NS & $43 \pm 18(n=28)$ & $16 \%$ \\
\hline $\mathrm{P}^{-} \mathrm{PO}_{4}{ }^{3-}\left(\mathrm{mg} \cdot \mathrm{L}^{-1}\right)$ & $26 \pm 11(n=27)$ & NS & $12 \pm 7(n=28)$ & NS \\
\hline
\end{tabular}




\section{Análise estatística}

Os valores utilizados para a análise estatística compreenderam somente os valores das amostragens simples e compostas do afluente e efluente dos wetlands referentes a 2014. Conforme a Tabela 3, em ambos os sistemas não se obteve diferença estatística $(\alpha=0,05)$ entre as médias das amostragens simples e compostas referentes aos parâmetros analisados. Dessa forma, levaram-se em consideração apenas as amostragens simples, devido ao maior conjunto de dados.

\section{Carregamento orgânico}

Considerando as concentrações de DBO e DQO afluente do wetland do sistema 1, conjuntamente com a vazão e a área superficial de dois quadrantes, a carga média aplicada nesse sistema foi de $43 \mathrm{~g}$ DBO m $\mathrm{m}^{-2} \cdot \mathrm{d}^{-1}$ e $87 \mathrm{~g}$ DQO $\mathrm{m}^{-2} \cdot \mathrm{d}^{-1}$ durante o segundo ano do monitoramento. Esses valores se aproximam quase três vezes mais do que o parâmetro de projeto, ao qual foi estabelecido um limite máximo de carregamento de 15 g DBO $\mathrm{m}^{-2} \cdot \mathrm{d}^{-1}$.

Durante o mesmo período o sistema 2 recebeu uma carga média de $0,94 \mathrm{~g} \mathrm{DBO} \mathrm{m}^{-2} \cdot \mathrm{d}^{-1}$ e $1,8 \mathrm{~g}$ DQO $\mathrm{m}^{-2} \cdot \mathrm{d}^{-1}$. Para esse sistema destaca-se que $\mathrm{o}$ parâmetro de projeto adotado para o dimensionamento do WCFV foi de 14,5 $\mathrm{g}$ DBO $\mathrm{m}^{-}$ ${ }^{2} \cdot \mathrm{d}^{-1}$, ou seja, o sistema recebeu uma carga bem abaixo do que o previsto, justificado porque o sistema trabalhava com características de fase inicial, ou seja, atendia apenas $5 \%$ da população prevista em projeto.

Essas altas e baixas taxas de carregamento aplicados nos wetlands referentes aos sistemas $1 \mathrm{e}$ 2 refletem no desempenho do tratamento, interferindo diretamente na velocidade de remoção de vários poluentes, entre eles a oxidação e a remoção completa da amônia.

\section{Remoção da matéria orgânica carbonácea}

As Figuras 5 e 6 apresentam, respectivamente, gráficos box plot das concentrações de DQO e DBO nos três pontos amostrados dos sistemas $1 \mathrm{e}$ 2.

Durante o período de estudo, a DQO do esgoto no último compartimento do RAC ou entrada do WCFV referente ao sistema 1 apresentou valores médios de $603 \mathrm{mg} . \mathrm{L}^{-1}$. Ao passar pelo $\mathrm{WCFV}$, os valores reduziram para $179 \mathrm{mg} . \mathrm{L}^{-1}$, indicando eficiência média de remoção de $70 \%$ e remoção média global de $75 \%$

No sistema 2 os valores de DQO na saída do tratamento primário apresentaram concentração média $157 \mathrm{mg} . \mathrm{L}^{-1}$, e na saída do WCFV os valores médios foram de $18 \mathrm{mg} . \mathrm{L}^{-1}$, apresentando eficiência de remoção de $88 \%$ e remoção média global de $93 \%$.

A eficiência de remoção do RAC em termos de DBO foi de $16 \%$ e $47 \%$ para os sistemas 1 e 2 respectivamente, e para o arranjo tecnológico a eficiência de remoção global dos sistemas foi de $88 \%$ e $97 \%$, respectivamente.

Em termos de matéria orgânica biodegradável, os valores de remoção dos decantodigestores de ambos os sistemas foram inferiores aos reportados por Hoffmann et al. (2011), que destacam como característica dos tanques com quatro a seis compartimentos localizados em locais de clima quente eficiência de $60 \%$ de remoção. Infere-se que essa eficiência não alcançada por parte desses reatores esteja relacionada com o aumento de sólidos nos compartimentos de digestão do RAC, visto que as duas unidades nunca foram limpas.

Tabela 3 - Resultado estatístico obtido com o teste ANOVA para as amostras simples e compostas do afluente e efluente dos wetlands referentes aos sistemas 1 e 2

\begin{tabular}{ccccc}
\hline \multirow{2}{*}{ Parâmetros } & \multicolumn{2}{c}{ Sistema 1 - $\mathbf{p}^{*}$ ANOVA } & \multicolumn{2}{c}{ Sistema 2 - $\mathbf{p}^{*}$ ANOVA } \\
\cline { 2 - 5 } & Afluente & Efluente & Afluente & Efluente \\
\hline $\mathrm{pH}$ & 0,09 & 0,192 & 0,270 & 0,598 \\
Alcalinidade $\left(\mathrm{mgCaCO} \mathrm{HL}^{-1}\right)$ & 0,442 & 0,877 & 0,435 & 0,921 \\
$\mathrm{DQO}\left(\mathrm{mg} \cdot \mathrm{L}^{-1}\right)$ & 0,313 & 0,494 & 0,330 & 0,229 \\
$\mathrm{SS}\left(\mathrm{mg} \cdot \mathrm{L}^{-1}\right)$ & 0,756 & 0,303 & 0,690 & 0,274 \\
$\mathrm{~N}-\mathrm{NH}_{4}^{+}\left(\mathrm{mg} \cdot \mathrm{L}^{-1}\right)$ & 0,445 & 0,497 & 0,737 & 0,794 \\
$\mathrm{P}_{-} \mathrm{PO}_{4}{ }^{3-}\left(\mathrm{mg} \cdot \mathrm{L}^{-1}\right)$ & 0,182 & 0,386 & 0,498 & 0,971 \\
\hline
\end{tabular}

Nota: *Se $p>a$, aceita-se $\mathrm{H}_{0}$ e se $\mathrm{p}<\mathrm{\alpha}$, rejeita-se $\mathrm{H}_{0}$ aceita-se $\mathrm{H}_{1}$. ANOVA foi aplicado com nível de significância de $5 \%$ $(a=0,05)$. - $H_{0}$ : não há diferença entre as amostras; - $H_{1}$ : há diferença entre as amostras. 
Figura 5 - Gráfico do tipo box plot destacando os valores médios, discrepantes e extremos de DQO obtidos com o monitoramento no primeiro compartimento do RAC, entrada e saída dos WCFV ao longo de 20 meses de monitoramento para os sistemas 1 e 2
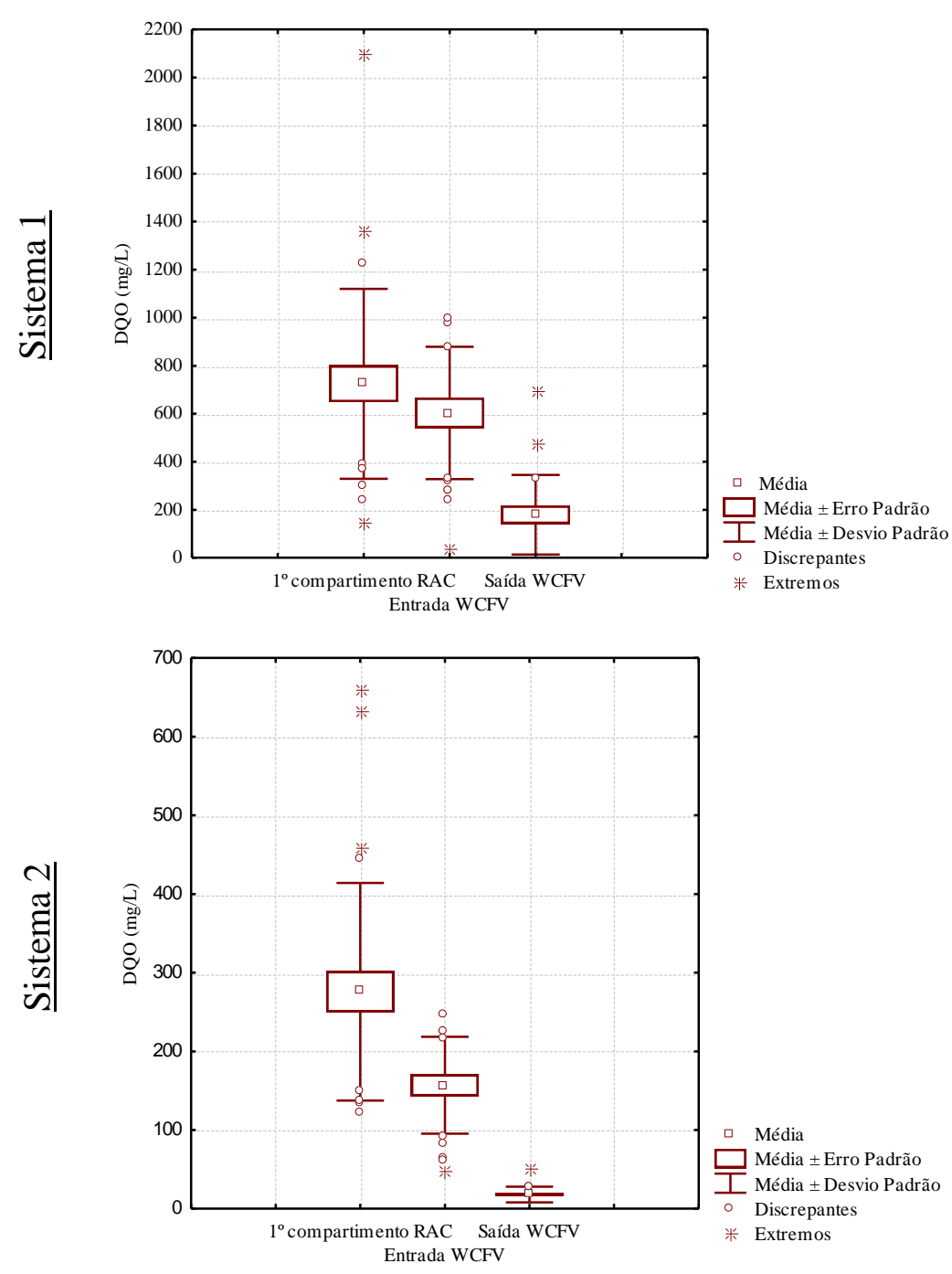
Figura 6 - Gráfico do tipo box plot destacando os valores médios, discrepantes e extremos de DBO obtidos com o monitoramento no primeiro compartimento do RAC, entrada e saída dos WCFV ao longo de 20 meses de monitoramento para os sistemas 1 e 2
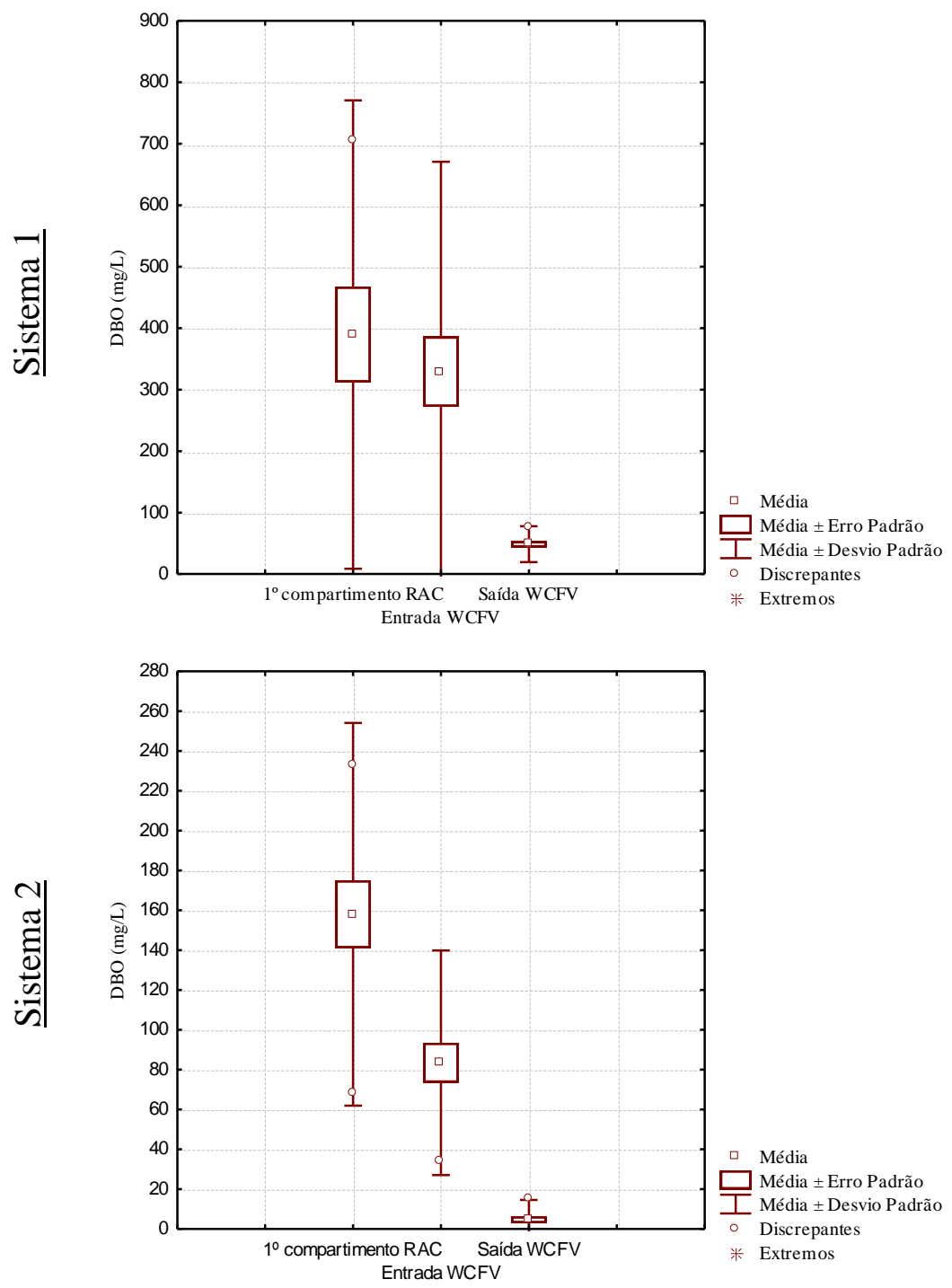

A combinação do decanto-digestor com os wetlands permitiu que os sistemas obtivessem altas eficiências de remoção em termos de DQO. Essa remoção é decorrente da sedimentação dos sólidos em suspensão e de processos de decomposição nas camadas superiores do filtro (ZHANG; GERSBERG; KEAT, 2009). A matéria orgânica é consumida e reduzida por micro-organismos tanto na zona aeróbia quanto na zona anaeróbia dentro do wetland (PHILIPPI; SEZERINO, 2004).

De acordo com a NBR 13969 (ABNT, 1997), em um conjunto de tanque séptico seguido de um filtro de areia ou vala de filtração a faixa provável de remoção desse poluente é de $40 \%$ a $75 \%$. Em ambos os casos a remoção de matéria orgânica pelo sistema RAC aliado a um WCFV encontra-se dentro do esperado para unidades de filtração.

\section{Desempenho de tratamento avançado}

\section{Remoção de sólidos suspensos}

A Figura 7 apresenta gráficos do tipo box plot das concentrações de SS nos três pontos amostrados dos sistemas 1 e 2 .

As concentrações de SS no primeiro compartimento do RAC referente ao sistema 1 foram em média $134 \mathrm{mg} . \mathrm{L}^{-1}$, e no último compartimento $109 \mathrm{mg} . \mathrm{L}^{-1}$. Na saída da unidade de filtração os valores residuais foram de $22 \mathrm{mg} . \mathrm{L}^{-1}$. 
Figura 7 - Gráfico do tipo box plot destacando os valores médios, discrepantes e extremos de SS obtidos com o monitoramento no primeiro compartimento do RAC, entrada e saída dos WCFV ao longo de 20 meses de monitoramento para os sistemas 1 e 2
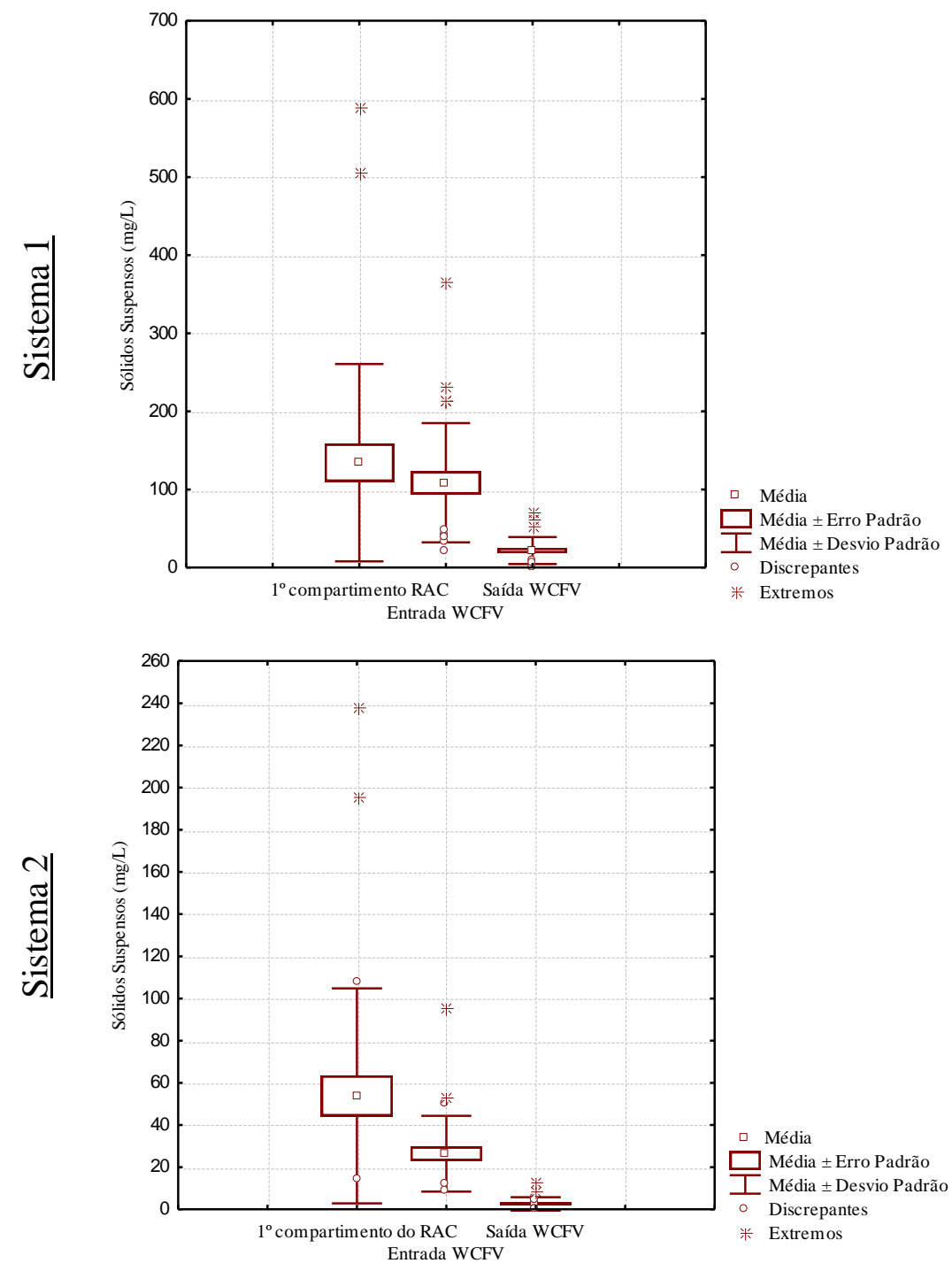

Destaca-se a baixa eficiência do decanto-digestor na retenção de sólidos, visto que a configuração com câmaras em séries visa principalmente aumentar essa porcentagem, no entanto esses valores limitaram-se a $19 \%$ de eficiência. Contudo, após a passagem pelo WCFV, o sistema obteve uma remoção média global de $83 \%$.

$\mathrm{O}$ pré-tratamento ineficiente acabou carregando o wetland com $13 \mathrm{~g}$ SS $\mathrm{m}^{-2} \cdot \mathrm{d}^{-1}$, valores bem superiores aos comparados em literatura. $\mathrm{O}$ sistema recebeu quase o triplo da carga recomendada em literatura, que é $5 \mathrm{~g} \mathrm{SS} \mathrm{m}^{-2} \cdot \mathrm{d}^{-1}$ (WINTER; GOETZ, 2003, HOFFMANN et al., 2011).

Alguns problemas foram observados nesta estação decorrentes do alto carregamento orgânico, como, por exemplo, o escoamento superficial, desencadeado pela deposição de SS junto ao material filtrante, fenômeno conhecido como colmatação.

Consequências desse fenômeno resultam em um mau funcionamento hidráulico, fazendo com que o esgoto não entre em contato com a rizosfera, consequentemente reduzindo a qualidade de tratamento do efluente (SEZERINO, 2006), limitando a ação dos micro-organismos, provocado pelo decréscimo da entrada de oxigênio no material filtrante, que não é suficiente para vários processos aeróbios, como degradação da matéria orgânica, e para a nitrificação (LANGERGRABER et al., 2003).

Contudo, o processo de colmatação é reversível. Para minimizar ou reverter esse problema, procedimentos como limpeza do decantodigestor e 
alternância dos quadrantes foram realizados. Este último já vinha sendo adotado na estação, contudo a alternância se dava de forma cruzada e percebeuse que, devido à obstrução da camada superior, o esgoto acabava percolando para as áreas em repouso, impedindo assim sua secagem. Dessa forma mudou-se a alternância da alimentação dos dois quadrantes em paralelo.

No sistema 2 a concentração média de SS no primeiro compartimento do RAC foi de $54 \mathrm{mg} . \mathrm{L}^{-1}$. Ao passar pelos três compartimentos de digestão do decantodigestor o esgoto afluente do wetland apresentou concentração média de $26 \mathrm{mg} . \mathrm{L}^{-1}$, e na saída da unidade de filtração os valores residuais foram de $3 \mathrm{mg} . \mathrm{L}^{-1}$. Destaca-se que $52 \%$ dos sólidos removidos foram retidos no decantodigestor e que o arranjo tecnológico (RAC + WCFV) apresentou eficiência de remoção de $94 \%$.

Para os SS a carga média aplicada permaneceu em $0,25 \mathrm{~g}$ SS $\mathrm{m}^{-2} \cdot \mathrm{d}^{-1}$, bem inferior ao máximo recomendado. Esse baixo carregamento aplicado no sistema tende a preservar as condições do escoamento no wetland, evitando assim o entupimento dos espaços vazios do material filtrante e consequentemente reduzindo o potencial de colmatação da unidade de tratamento.

\section{Transformação do nitrogênio}

Em termos de nitrogênio amoniacal, a concentração média encontrada no último compartimento do RAC referente ao sistema 1 foi de $98 \mathrm{mg} . \mathrm{L}^{-1}$. Essa alta concentração foi atribuída ao despejo de urina (principalmente pelo uso de mictórios) no estabelecimento comercial. Após passar pelo wetland o efluente foi lançado na rede de drenagem pluvial apresentando concentrações médias de $54 \mathrm{mg} \mathrm{NH} \mathrm{NH}_{4} \cdot \mathrm{L}^{-1}$. A eficiência média de remoção global de $\mathrm{N}-\mathrm{NH}_{4}{ }^{+}$nesse sistema foi da ordem de $47 \%$. Desse percentual de amônia removida $38 \%$ foram transformados em nitrato pelo processo de nitrificação.

IWA (INTERNATIONAL..., 2000) e Kadlec e Wallace (2009), destacam que o principal mecanismo de remoção de nitrogênio orgânico nos wetlands é via bioquímica, conhecida como nitrificação seguida da desnitrificação. Outros mecanismos de remoção podem ter contribuído para a redução da amônia afluente, como a adsorção no material filtrante, assimilação pelas macrófitas, bem como a diluição pela precipitação pluviométrica.

A Figura 8 apresenta um gráfico evolutivo das concentrações de nitrogênio nos três pontos amostrados do sistema 1 .

A carga de amônia aplicada no wetland foi de $15 \mathrm{~g}$ $\mathrm{m}^{-2} \cdot \mathrm{d}^{-1}$. Embora houvesse redução de amônia após passar pelo wetland, as concentrações de saída ainda se mantiveram elevadas. $\mathrm{O}$ nitrato foi produzido, mas as concentrações foram relativamente baixas, se comparadas com as concentrações de amônia afluente, mostrando que a nitrificação completa não aconteceu. Segundo Kantawanichkul, Kladprasert e Brix (2009), isso indica que a operação e a estrutura física do sistema não proporcionaram tempo de retenção suficiente para permitir o contato com as bactérias que são responsáveis por promover a nitrificação.

No sistema 2 o WCFV apresentou remoção constante de $\mathrm{N}_{-} \mathrm{NH}_{4}{ }^{+}$durante todo o período de monitoramento. Concentrações médias de $\mathrm{N}-\mathrm{NH}_{4}{ }^{+}$ afluente do WCFV de $43 \mathrm{mg} . \mathrm{L}^{-1}$ e efluente de 3 mg. $L^{-1}$ representaram $93 \%$ de eficiência de remoção. $\mathrm{O}$ processo de nitrificação também ocorreu. Isso foi verificado pelo aumento da concentração de $\mathrm{N}_{-} \mathrm{NO}_{3}{ }^{-}$no efluente final do wetland, alcançando valores médios de $11 \mathrm{mg} . \mathrm{L}^{-1}$. Com base nesses valores constata-se que dos $93 \%$ de $\mathrm{N}_{-} \mathrm{NH}_{4}{ }^{+}$removida $27 \%$ foram devidos à nitrificação.

A Figura 9 apresenta um gráfico evolutivo das concentrações de nitrogênio nos três pontos amostrados do sistema 2.

Como se obteve alta remoção de amônia e de matéria orgânica, acredita-se que o oxigênio não foi um fator limitante no processo de transformação do nitrogênio. Como as características construtivas do WCFV com fundo saturado permitem condições para a remoção e/ou transformação do nitrogênio devido às condições redutoras existentes nos $20 \mathrm{~cm}$ de fundo saturado, infere-se que pode ter ocorrido o processo de desnitrificação.

Além da desnitrificação, a baixa concentração de $\mathrm{N}_{-} \mathrm{NH}_{4}^{+}$no efluente final durante as quatro estações do ano pode ser atribuída à diluição promovida pela precipitação pluviométrica, visto a grande área superficial do wetland. 
Figura 8 -1 Concentrações de $\mathrm{N}-\mathrm{NH}_{4}{ }^{+}$no afluente e efluente do WCFV e concentrações de $\mathrm{N}-\mathrm{NO}_{2}{ }^{-}$e $\mathrm{N}-$ $\mathrm{NO}_{3}{ }^{-}$no efluente do WCFV ao longo do período de estudo referentes ao sistema 1

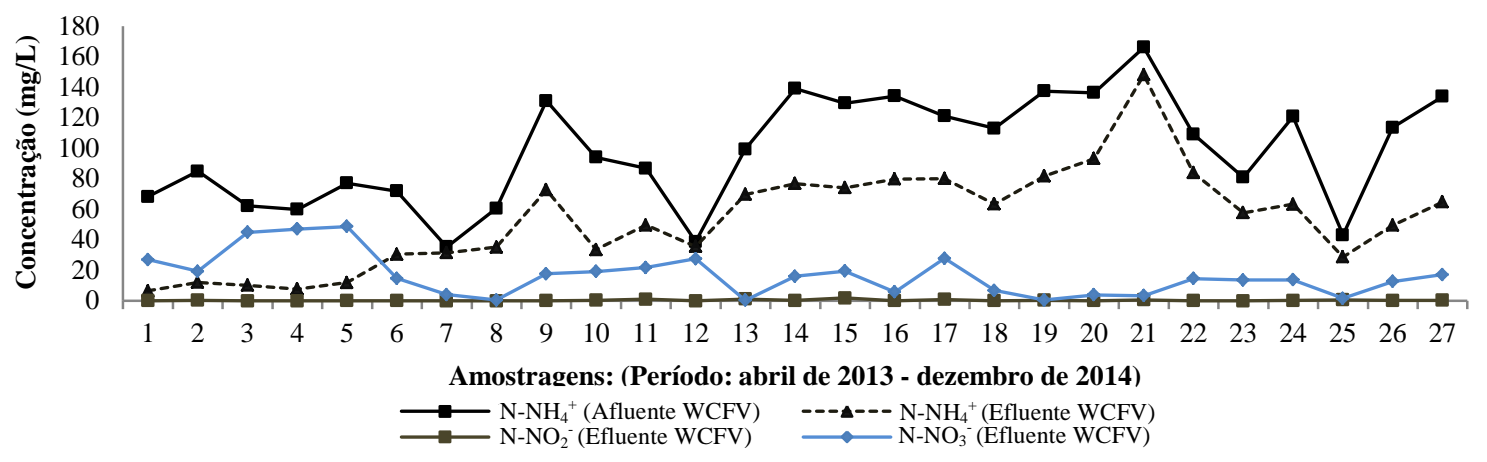

Figura 9 -2 Concentrações de $\mathrm{N}-\mathrm{NH}_{4}{ }^{+}$no afluente e efluente do WCFV e concentrações de $\mathrm{N}-\mathrm{NO}_{2}{ }^{-}$e $\mathrm{N}$ $\mathrm{NO}_{3}^{-}$no efluente do WCFV ao longo do período de estudo referentes ao sistema 2

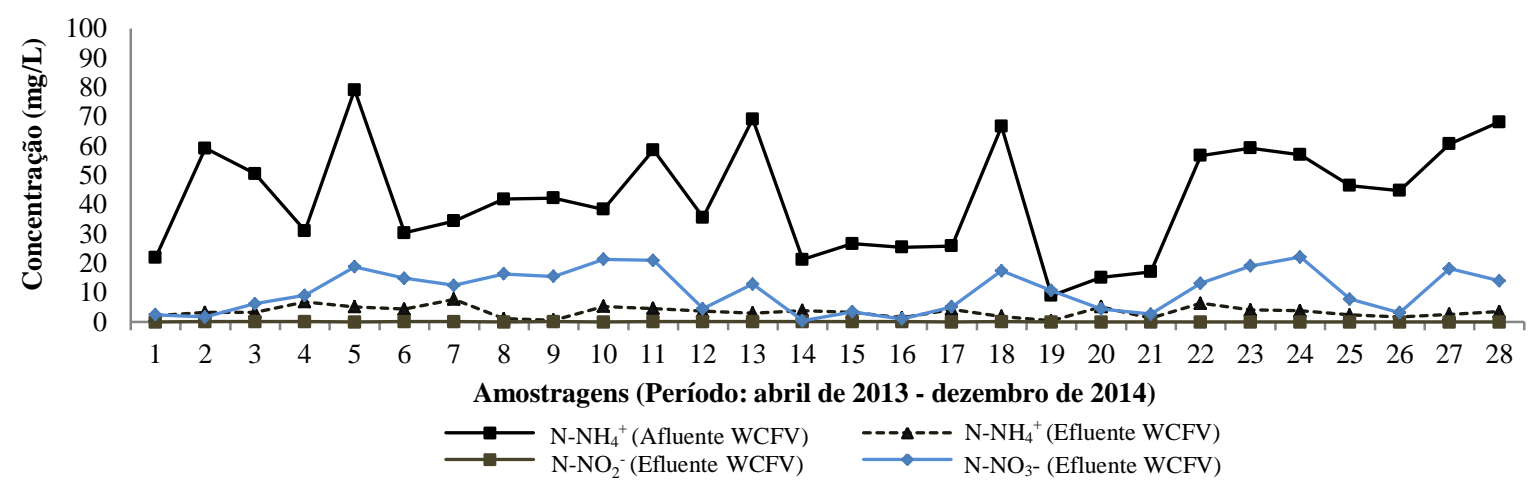

\section{Retenção de fósforo orgânico dissolvido}

A concentração média de ortofosfato no primeiro compartimento do RAC referente ao sistema 1 variou de $27 \pm 11 \mathrm{mg} . \mathrm{L}^{-1}$, representando valores superiores à faixa característica do esgoto doméstico, que, segundo Von Sperling (1996), varia entre 3 e 9 mg. $\mathrm{L}^{-1}$. Esses altos valores condizem com a rotina dos funcionários dentro da empresa, como, por exemplo, o uso em grande quantidade de detergentes usualmente utilizados nas tarefas de limpeza (na cozinha e na limpeza do chão) e cuidados pessoais, como sabonete líquido, que contém fosfatos em sua composição.

Segundo Korkusuz, Beklioglu e Demirer (2004), além do aumento na concentração de fósforo, o uso em grande quantidade de detergentes resulta, por sua vez, em aumentos acentuados de $\mathrm{N}-\mathrm{NH}_{4}{ }_{4}$. Consequentemente, as concentrações de DQO afluente também são afetadas pela quantidade de poluentes orgânicos presente nos detergentes.

A eficiência do WCFV com 5 anos de operação recebendo concentrações médias afluentes de 26 $\mathrm{mg} \mathrm{PO}_{4}{ }^{3-} \cdot \mathrm{L}^{-1}$ apresentou remoção de ortofosfato na faixa de $61 \%$, com concentração residual de 10 mg. $\mathrm{L}^{-1}$.
No sistema 2 a concentração média de ortofosfato no afluente do wetland foi de $12 \mathrm{mg} . \mathrm{L}^{-1}$, e no efluente tratado, $0,8 \mathrm{mg} . \mathrm{L}^{-1}$, representando remoção média percentual da unidade de filtração de $93 \%$. Deduz-se que essa alta remoção de fósforo foi proporcionada pela adsorção química no material filtrante, uma vez que é o mecanismo de remoção predominante do ortofosfato. Contudo, segundo Brix e Arias (2005), a perda de eficiência na remoção de fósforo em wetlands construídos por adsorção e precipitação no material filtrante é cada vez mais limitada após algum tempo de operação.

A capacidade de extração de fósforo ortofosfato pelas plantas também ocorre, porém em ritmo mais lento em comparação com a adsorção no material filtrante (LUDERITZ; GERLACH, 2002).

\section{Avaliação bacteriológica}

No sistema 1 a concentração média de E. coli encontrada no último compartimento do RAC ou entrada do WCFV foi de 1,37 x $10^{8} \mathrm{NMP} .100 \mathrm{~mL}^{-1}$, e, após a passagem pelo wetland, a concentração foi de $1,42 \times 10^{7} \mathrm{NMP} .100 \mathrm{~mL}^{-1}$. Percebe-se que 
essa unidade não apresentou boa remoção, com decaimento de apenas $0,98 \log _{10}$.

No sistema 2 a concentração de $E$. coli foi de 3,21 x $10^{7}, 2,43 \times 10^{6}$ e $2,19 \times 10^{4}$ NMP. $100 \mathrm{~mL}^{-1}$, para o primeiro, segundo e terceiro pontos amostrados respectivamente. O decaimento global médio de $E$. coli referente ao arranjo tecnológico foi de 2,05 $\log _{10}$.

Neste último sistema o WCFV mostrou ter melhor capacidade na remoção de E. coli, o que sugere que a remoção ocorreu principalmente por mecanismos associados com filtração e pelo tempo maior de retenção hidráulica no sistema, proporcionada pelo fundo saturado.

\section{Atendimento aos parâmetros de lançamento}

Conforme valores apresentados neste estudo, os resultados de DBO obtidos no sistema 1 e 2 atendem à Resolução Conama 430/2011 (BRASIL, 2011) e à Lei Estadual 4.675/2009 (SANTA..., 2009) em termos de concentração no efluente final, com 48 e $5 \mathrm{mg} . \mathrm{L}^{-1}$, e em termos de eficiência de remoção, com $88 \%$ e $97 \%$ respectivamente.

Com relação ao parâmetro nitrogênio amoniacal, destaca-se que não há na legislação valores-limite para lançamento referentes ao esgoto sanitário, mas sim aos efluentes líquidos de distintas origens, conforme a Resolução Conama 430/2011 (BRASIL, 2011). Ao se considerar, portanto, a referida resolução, a periodicidade do enquadramento de lançamento de amônia no efluente do sistema 1 foi de $18 \%$ do total de 27 amostragens, cujas concentrações foram inferiores ao valor máximo de $20 \mathrm{mg} \mathrm{NH} \mathrm{NH}_{4} \mathrm{~L}^{-1}$. Contudo, o efluente sanitário tratado deste sistema é lançado em rede pluvial, para a qual não há exigência legal de limite de lançamento. Já no sistema 2, em todas as amostragens (100\%), o efluente final apresentou concentrações abaixo do valor de referência de 20 $\mathrm{mg} \mathrm{NH} \mathrm{N}_{4} \mathrm{~L}^{-1}$ preconizado pela Resolução Conama 430/2011, referente ao lançamento de efluentes líquidos.

Em ambos os sistemas a remoção de sólidos foi superior ao mínimo permitido, que é de $20 \%$ de eficiência de remoção. $\mathrm{O}$ arranjo tecnológico referente ao sistema 1 removeu cerca de $83 \%$ dos sólidos suspensos, e o sistema 2 removeu $94 \%$.

$\mathrm{Na}$ Tabela 4 apresentam-se os valores de alguns parâmetros analisados durante o monitoramento dos sistemas 1 e 2, juntamente com as faixas de valores-limite para lançamento de esgoto sanitário de acordo com a legislação ambiental pertinente.

Tabela 4 - Comparativo em termos de qualidade dos efluentes dos sistemas 1 e 2 com as normativas e legislações aplicáveis

\begin{tabular}{|c|c|c|c|c|c|c|c|}
\hline \multirow{2}{*}{ Parâmetros } & \multicolumn{2}{|c|}{ Sistema 1} & \multicolumn{2}{|c|}{ Sistema 2} & \multirow{2}{*}{$\begin{array}{c}\text { NBR } \\
\text { 13969/97 } \\
\text { (ABNT, } \\
\text { 1997) } \\
\text { Mín - Máx }\end{array}$} & \multirow{2}{*}{$\begin{array}{c}\begin{array}{c}\text { Resolução } \\
\text { Conama 430 } \\
\text { (BRASIL, } \\
\text { 2011) }\end{array} \\
\text { Mín - Máx }\end{array}$} & \multirow{2}{*}{$\begin{array}{c}{\text { Lei } \mathrm{n}^{\circ}} \\
14675 / 2009 \\
\text { (SANTA.... } \\
\text { 2009) } \\
\text { Mín - Máx }\end{array}$} \\
\hline & $\begin{array}{c}\text { Eficiência } \\
(\%)\end{array}$ & $\begin{array}{c}\text { Concentração } \\
(\mathrm{mg} / \mathrm{L})\end{array}$ & $\begin{array}{c}\text { Eficiência } \\
(\%)\end{array}$ & $\begin{array}{c}\text { Concentração } \\
(\mathrm{mg} / \mathrm{L})\end{array}$ & & & \\
\hline $\mathrm{pH}$ & - & 6,3 & - & 6,5 & $6-9$ & $5-9$ & $6-9$ \\
\hline DQO & $75 \%$ & 179 & $93 \%$ & 18 & $\begin{array}{l}\text { Inferior a } \\
150 \mathrm{mg} / \mathrm{L} \\
\end{array}$ & ND & ND \\
\hline $\mathrm{DBO}_{5}{ }^{20}$ & $88 \%$ & 48 & $97 \%$ & 5 & $\begin{array}{l}\text { Inferior a } \\
60 \mathrm{mg} / \mathrm{L}\end{array}$ & $\begin{array}{c}120 \mathrm{mg} / \mathrm{L} \\
\text { ou } \\
\text { Eficiência } \\
\text { de remoção } \\
\text { de } 60 \%\end{array}$ & $\begin{array}{c}60 \mathrm{mg} / \mathrm{L} \text { ou } \\
\text { Eficiência } \\
\text { de remoção } \\
\text { de carga de } \\
80 \%\end{array}$ \\
\hline SS & $83 \%$ & 22 & $94 \%$ & 3 & ND & $\begin{array}{c}\text { Eficiência } \\
\text { de remoção } \\
\text { de } 20 \%\end{array}$ & ND \\
\hline $\mathrm{N}-\mathrm{NH}_{4}{ }^{+}$ & $47 \%$ & 54 & $94 \%$ & 3 & ND & $20 \mathrm{mg} / \mathrm{L} *$ & ND \\
\hline $\mathrm{N}-\mathrm{NO}_{3}{ }^{-}$ & - & 17 & - & 11 & ND & ND & ND \\
\hline $\mathrm{P}-\mathrm{PO}_{4}{ }^{3-}$ & $63 \%$ & 10 & $93 \%$ & 1 & ND & ND & $\begin{array}{c}* \text { Eficiência } \\
\text { de remoção } \\
\text { de } 75 \%\end{array}$ \\
\hline
\end{tabular}

Nota: ND - não definido; e *parâmetro-limite relacionado aos efluentes líquidos. 


\section{Conclusão}

Com base em um período de 2 anos de monitoramento em dois sistemas de tratamento descentralizado de esgotos, ambos compostos de tratamento primário (decantodigestor do tipo reator anaeróbio compartimentado - RAC) seguido de wetland construído de escoamento subsuperficial de fluxo vertical (WCFV), pode-se chegar às conclusões a seguir.

\section{Sistema 1}

O sistema de tratamento de esgotos composto de RAC seguido de WCFV em operação há 5 anos recebendo esgotos de banheiros, cozinha e lavagem de pisos de uma empresa apresentou, a partir do monitoramento contínuo de 2 anos, variações no desempenho, destacando-se o seguinte:

(a) submetendo o WCFV a um carregamento médio de $13 \mathrm{~g} \mathrm{SS} \mathrm{m}^{-2} \cdot \mathrm{d}^{-1} \mathrm{e} 87 \mathrm{~g}$ DQO $\mathrm{m}^{-2} \cdot \mathrm{d}^{-1}$, identificaram-se indícios de colmatação nele;

(b) apesar de o WCFV ter operado com alto carregamento orgânico, apresentou eficiência média de remoção de DQO de $70 \%$;

(c) a eficiência média de remoção global de $\mathrm{N}$ $\mathrm{NH}_{4}{ }^{+}$nesse sistema foi da ordem de $47 \%$, sendo $38 \%$ devidos à transformação de $\mathrm{N}^{-\mathrm{NH}_{4}}{ }^{+} \mathrm{em} \mathrm{N}$ $\mathrm{NO}_{3}$; e

(d) a nitrificação foi evidente nesse módulo, contudo o início do fenômeno de colmatação do maciço filtrante no wetland teve influência negativa nesse processo.

\section{Sistema 2}

O sistema de tratamento de esgotos composto de RAC seguido de WCFV com fundo saturado em operação há 9 anos recebendo esgotos sanitários de um condomínio residencial (com ocupação referente a $5 \%$ da população máxima de projeto) apresentou, a partir do monitoramento contínuo de 2 anos, variações no desempenho, destacando-se o seguinte:

(a) submetendo o WCFV a reduzidos carregamentos médios de $0,94 \mathrm{~g} \mathrm{DBO} \mathrm{m}^{-2} \cdot \mathrm{d}^{-1}, 1,8$ $\mathrm{g}$ DQO m $\mathrm{m}^{-2} \cdot \mathrm{d}^{-1}$ e $0,25 \mathrm{~g} \mathrm{SS} \mathrm{m}^{-2} \cdot \mathrm{d}^{-1}$, ele apresentou eficiências médias de remoção em termos de concentração de $94 \%, 93 \%$ e $94 \%$ para DQO, SS e $\mathrm{P}_{-} \mathrm{PO}_{4}{ }^{3-}$, respectivamente;

(b) observou-se remoção média de $93 \%$ de nitrogênio amoniacal, sendo $27 \%$ desta remoção devidos à nitrificação no WCFV; e (c) apesar da alta remoção da amônia, a baixa formação de nitrato indica outras vias de remoção, como a desnitrificação.

A avaliação do projeto e o modo de operação dos sistemas demonstram que o desempenho do tratamento é dependente das condições hidráulicas, da taxa de carregamento, do tempo de retenção hidráulica e do modo de alimentação.

Os wetlands, quando projetados e operados de maneira adequada, apresentam eficiência compatível com outras tecnologias que promovem o tratamento secundário e terciário, mostrando-se como uma alternativa tecnológica de grande potencial ao promover o tratamento de esgoto doméstico sob o contexto da descentralização.

\section{Referências}

\author{
AMERICAN PUBLIC HEALTH \\ ASSOCIATION; AMERICAN WATER WORKS \\ ASSOCIATION; WATER ENVIRONMENT \\ FEDERATION. Standard Methods for the \\ Examination of Water and Wastewater. 20. ed. \\ Washington: APHA, 1998.
}

AMERICAN PUBLIC HEALTH

ASSOCIATION; AMERICAN WATER WORKS

ASSOCIATION; WATER ENVIRONMENT

FEDERATION. Standard Methods for the

Examination of Water and Wastewater. 21. ed. Washington: APHA, 2005.

ASSOCIAÇÃO BRASILEIRA DE NORMAS TÉCNICAS. NBR 7229: projeto, construção e operação de sistemas de tanques sépticos. Rio de Janeiro, 1993.

\section{ASSOCIAÇÃO BRASILEIRA DE NORMAS TÉCNICAS. NBR 13969: projeto, construção e operação de unidades de tratamento complementares e disposição final dos efluentes de tanques sépticos: procedimentos. Rio de Janeiro, 1997.}

BRASIL. Conselho Nacional do Meio Ambiente CONAMA. Resolução $n^{\circ} 430$ de 13 de maio de 2011. Diário Oficial da União, Brasília, 16 maio 2011.

BRIX, H.; ARIAS, C. A.; The Use of Vertical Flow Constructed Wetlands for On-Site Treatment of Domestic Wastewater: New Danish guidelines. Science Direct: Ecological Engineering, v. 25, n. 5, p. 491-500, 2005.

HO, G. Technology for Sustainability: the role of onsite, small and community scale technology.

Water Science \& Technology, v. 51, n. 10, p. 1520, 2005. 
HOFFMANN, H. et al. Technology Review of Constructed Wetlands Subsurface Flow Constructed Wetlands for Greywater and Domestic Wastewater Treatment. Eschborn: Giz, 2011.

INTERNATIONAL WATER ASSOCIATION. Constructed Wetlands for Pollution Control: processes, performance, design and operation. scientific and technical. London: IWA Publishing, 2000. Report $\mathrm{N}^{\mathrm{o}} .8$

KADLEC, R. H.; WALLACE, S. D. Treatment Wetlands. $2^{\text {th. }}$ Ed. Boca Raton: CRC, Taylor \& Francis Group, 2009.

KANTAWANICHKUL, S.; KLADPRASERT, S., BRIX, H. Treatment of High-Strength Wastewater in Tropical Vertical Flow Constructed Wetlands Planted With Typha Angustifolia and Cyperus Involucratus, Ecological Engineering, v. 35, n. 2, p. 238-247, 2009.

KAYSER, K.; KUNST, S. Processes in VerticalFlow Reed Beds: nitrification, oxygen transfer and soil clogging. Water Science and Technology, v. 51, n. 9, p. 177-184, 2005.

KORKUSUZ, E. A.; BEKLIOGLU, M.; DEMIRER, G. N. Treatment Efficiencies of the Vertical Flow Pilot-Scale Constructed Wetlands for Domestic Wastewater. Turkish Journal of Engineering and Environmental Sciences, v. 28, p. 333-344, 2004.

LANGERGRABER, G. Simulation of Subsurface Flow Constructed Wetlands: results and further research needs. Water Science Technology, v. 48, p. 157-68, 2003.

LUDERITZ, V.; GERLACH, F. Phosphorus Removal in Different Constructed Wetlands. Acta Biotechnologica, v. 22, n. 1, p. 91-99, 2002.

MASSOUD, M. A.; TARHINI, A.; NASR, J. A. Decentralized Approaches to Wastewater Treatment and Management: applicability in developing countries. Journal of Enverinmental Management, v. 90, n. 1, p. 652-659, 2009.

METCALF \& EDDY. Wastewater Engineering: treatment, disposal and reuse. $3^{\text {th }}$. ed. New York: Metcalf \& Eddy, 1991.

PHILIPPI, L. S.; SEZERINO, P. H. Aplicação de Sistemas Tipo Wetlands no Tratamento de Águas Residuárias: utilização de filtros plantados com macrófitas. Florianópolis: Edição do autor, 2004.
PLATZER, C. Design Recomendation for Subsurface Flow Constructed Wetlands for Nitrification and Denitrification. Water Scince Technology, v. 40, n. 3, p. 257-263, 1999.

PLATZER, C. et al. Dimensionamento de Wetland de Fluxo Vertical Com Nitrificação: adaptação de modelo europeu para as condições climáticas do Brasil. In: CONGRESSO BRASILEIRO DE ENGENHARIA SANITÁRIA AMBIENTAL, 24., Belo Horizonte, 2007. Anais... Belo Horizonte: ABES, 2007.

SANTA CATARINA. Lei 14.675, de 13 de abril de 2009.

SEZERINO, P. H. Potencialidade dos Filtros Plantados Com Macrófitas (Constructed Wetlands) no Pós-Tratamento de Lagoas de Estabilização Sob Condições de Clima Subtropical. Florianópolis, $2006.171 \mathrm{f}$. Tese (Doutorado em Engenharia Ambiental) - Curso de Engenharia Ambiental, Universidade Federal de Santa Catarina, Florianópolis. 2006.

SEZERINO, P. H. et al. Constructed Wetlands and Sand Filter Applied as Onsite Post-Treatment of Anaerobic Efluente. Water Practice \& Technology, v. 7, n. 3, 2012.

VON SPERLING, M. Princípios de Tratamento Biológico de Águas Residuárias: introdução à qualidade das águas e ao tratamento de esgotos. Belo Horizonte: Departamento de Engenharia Sanitária e Ambiental, Universidade Federal de Minas Gerais, 1995. v. 1.

VYMAZAL, J.; KROPFELOVÁ, L. Wastewater Treatment in Constructed Wetlands With Horizontal Sub-Surface Flow. Republica Tcheca: Springer, 2008.

WINTER, K. J.; GOETZ, D. The Impact of Sewage Composition on the Soil Clogging Phenomena of Vertical Flow Constructed

Wetlands. Water Science \& Technology, v. 48, n. 5, p. 9-14, 2003.

ZHANG, D.; GERSBERG, R. M.; KEAT, T. S. Review Constructed Wetlands in China. Ecological Engineering, v. 35, p. 1367-1378, 2009.

\section{Agradecimentos}

Os autores agradecem o Conselho Nacional de Desenvolvimento Científico e Tecnológico CNPq, a Fundação Nacional de Saúde - FUNASA e à empresa Rotária do Brasil Ltda, pelo suporte financeiro e operacional da pesquisa. 


\section{Camila Maria Trein}

Universidade de Rio Verde | Av. Ministro João Alberto, 310, Campus Caiapônia | Nova Caiapônia - GO - Brasil | CEP 75850-000 | Tel.: (64) 36631892 | E-mail: camilatrein@yahoo.com.br

\section{Catiane Pelissari}

Departamento de Engenharia Sanitária e Ambiental, Centro Tecnológico | Universidade Federal de Santa Catarina | Campus Universitário, Trindade | Florianópolis - SC - Brasil | CEP 88040-970 | Tel.: (48) 37212606 | E-mail: catianebti@gmail.com

\section{Heike Hoffmann}

Rotária do Brasil Ltda. | Rua Teodoro Manoel Dias, 421, Santo Antônio de Lisboa | Florianópolis - SC - Brasil | CEP 88050-540 | Tel.: (048) 3234-3164 | E-mail: heike@rotaria.net

\section{Christoph Julius Platzer}

Rotária do Brasil Ltda. | E-mail: chr@rotaria.net

\section{Pablo Heleno Sezerino}

Departamento de Engenharia Sanitária e Ambiental, Centro Tecnológico | Universidade Federal de Santa Catarina | E-mail: pablo.sezerino@ufsc.br

\section{Revista Ambiente Construído}

Associação Nacional de Tecnologia do Ambiente Construído

Av. Osvaldo Aranha, $99-3^{\circ}$ andar, Centro

Porto Alegre - RS - Brasil

CEP $90035-190$

Telefone: +55 (51) 3308-4084

Fax: +55 (51) 3308-4054

www.seer.ufrgs.br/ambienteconstruido

E-mail: ambienteconstruido@ufrgs.br 